\title{
Recognising and Valuing Student Engagement in Science Museums
}

Student engagement with museum content is integral to the mission of many institutions, including science museums. Our research utilises a sociological lens to bring a new perspective on engagement in such spaces. Specifically, we draw on qualitative data from student visits to a science museum to explore what engagement might be possible, by whom, under what circumstances. The students in focus are of underrepresented backgrounds in the museum, and do not have high levels of science capital. Our findings reveal that moments of engagement occur when there is alignment between personal habitus and capital - the students' dispositions and practices - and the field, the museum's conventions and rules, as well as its objects and exhibits. However, this engagement was often with the historical or social aspects of exhibits, rather than the science behind them. We propose this approach to engagement as a useful reflection tool for museum practitioners.

Keywords: audiences, Bourdieu, engagement, reflective practice, science museums

\section{Introduction}

Visitor engagement with science is a core aim of science museums and centres. Engagement with science features invariably in mission statements, exhibition intended outcomes, project objectives, programme rationales, and strategic plans. Described as the 'holy grail of learning' (Sinatra, Heddy, and Lombardy 2015) and 'inherent' to the learning process (Boekaerts 2016), engagement also has a hefty presence in museum and science education literature. For the most part, the literature focusses on measuring, proving, and improving engagement, especially among school students, because this has been shown to lead to 'deeper' science learning and robust educational outcomes (Barriault and Pearson 2010; Bell et al. 2009; Fredricks, Blumenfeld, and Paris 2004). Compelling as it is, such work often tends to concentrate either on the (dis)engaged individual or the effectiveness of the exhibit or museum activity in question. This paper proposes an understanding of student engagement in science museums utilising a sociological lens that extends and complements analyses of engagement currently prevalent in the literature (Author 3 et al. in press). We use a Bourdieu- 
inspired perspective to examine the conditions that enable student engagement in a science museum setting. By doing so, we aim to challenge the narrow perspectives on what kinds of engagement tend to be expected and seen as desirable from the museums' point of view.

Our study is grounded in observations of students as part of a wider science education intervention programme that involved researchers working with school groups for a year at a time over four years. Museum visits were incorporated in the design of the project and we argue that understanding student engagement in the museum is an important step towards inclusive science education practice. In this paper, we report on students' behaviour and activities during museum visits with school and family, and interpret these actions from a sociological standpoint. We consider the extent to which individuals' behaviours align with the implicit expectations contained within a science museum environment and the extent to which their resources (e.g. their existing knowledge, perceptions, attitudes and experiences) facilitate their engagement within this space. We did not look for 'ideal' instances of engagement with science, which are often elusive, especially during school visits, or for cases of disengagement and disempowerment that have been documented elsewhere in the project (Archer et al. 2016). Instead, we chose to focus on subtler, and perhaps more fleeting instances of engagement 'in the moment', when some engagement occurs, whether with science content or not. We do so because such moments have often been overlooked, despite their potential to open up opportunities for further, deeper and more meaningful connections. Moreover, in identifying such connections, museums may be able to build on and extend them into further engagement.

\section{Conceptual framing}

Interpretations of engagement in science museums

We believe that research-informed museum practice can be achieved when key terms, such as learning and engagement, are explicitly defined and theoretically grounded (e.g. Gutwill, 
Hido, and Sindof 2015). When it comes to engagement, the literature from the informal science education sector ranges from traditional visitor studies (e.g. measuring time spent in front of an exhibit (Bitgood 2009)), to research drawing on disciplines such as educational psychology, (see for example Azevedo, 2015; Sinatra, Hedy, and Lombardy, 2015), which can lead to a strong focus on content knowledge (Bell et al. 2009; Hauan and Kolstø 2014) and cognitive engagement with science content (Fredricks et al. 2004). Studies on visitor engagement in science museums tend to focus primarily on the visitor or the direct interaction between the visitor and the exhibit and the characteristics of this interaction (for a review see e.g. Mutjaba et al 2018). Some authors have developed sophisticated tools that seek to capitalise on such characteristics. For example, Barriault and Pearson's (2010) visitor engagement framework is based on observable visitor behaviours around exhibits that are translated into discrete learning categories. These authors argue that as the visitor goes through the stages of engagement (initiation, transition, breakthrough), so the learning increases. This approach is designed as practical research tool to assess the engaging effectiveness of an exhibit. More recently, Hillman and colleagues (2016) were able to map students' 'traces of engagement' by using smartphone data, in an attempt to decode meaningmaking during a science museum visit. Employing a performative and spatial perspective, that study regarded students' paths and narrative production (as opposed to time spent) as indicative of engagement with the exhibits.

Following a similar strand, other studies focus on factors that instigate and maximise engaged, measurable behaviour during a visit. For instance Block et al. (2015) studied the impact of group characteristics on the engagement of visitors with interactive exhibits. They quantified engagement in terms of time spent in front the exhibit and interacting with scientific concepts. Their findings, based on an automatic grouping algorithm and two years of observations, reveal that age, social composition (parents and children), behaviours 
(talking and pointing), but most importantly, the size of a group determine the level of engagement with the exhibit (with longer dwelling time and more scientific concepts regarded as the highest level). In a different example, the Active Prolonged Engagement project was developed by the Exploratorium team as a blueprint for exhibit development that maximizes possibilities for visitor-authored questions, activity and discovery (Humphrey and Gutwill 2005). Building on this, the EDGE (Exhibit Designs for Girls' Engagement) project identified design attributes for specifically engaging girls at STEM exhibits (Danstep and Sindorf 2016).

Other studies focus on the way family dynamics play out during the visit, where for example parents can be a 'bridge' or 'barrier' to the child's engagement with the content on display (e.g. Zimmerman, Perin and Bell 2010). In any case, these approaches to understanding engagement in informal education settings tend to concentrate on visitors' behaviour and social interaction, and/or the individual characteristics of the exhibit (Mutjaba et al 2018; Schwan, Grajal and Lewalter 2014).

These interpretations of engagement can be neatly mapped onto 'the museum experience' model, consisting of personal, physical and sociocultural contexts (Falk and Dierking 2000, 2013). The cognitive and emotional processes manifested in visitor behaviour around exhibits correspond to the personal context. The social fabric of the visit also impacts on the emotional and behavioural aspects of visitor engagement, as does the physical context. Interventions to increase and improve engagement thus tend to focus on the person's relationship with the exhibit and the role of facilitation (e.g. Knutson et al. 2016). While the museum experience model is helpful in drawing attention to the multiple contexts that influence learning, we argue that a more analytical gaze into the 'fields of value' established by the institution (Dicks 2016, 53) holds promise for extending our understanding of engagement even further. More specifically, we extend our efforts to interpret student 
engagement by attending to behaviours and norms that are embedded, 'allowed', or expected in the museum. We do not regard the museum environment as a neutral setting where exposure to science may or may not lead to visitor engagement. Rather, engagement in the science museum is very much determined by the 'rules of game' which are scripted in said embedded, 'allowed' and expected norms.

\section{A sociological standpoint to engagement in science museums}

In this paper, we add a sociological lens to existing interpretations of engagement in science museums, which we think complements the sector's understanding of visitor experience and audience development efforts. Our insights on engagement address museum practice and its struggles to include underserved audiences meaningfully (see also Dicks 2016). We base our approach to engagement on 'science capital' - a concept originally developed to explain patterns in science participation among student populations in England (Colleague and Author 1 2017; Colleagues and Author 1 2015) and later put into practice as an approach to school science teaching (Author 3 and colleagues 2017; Author 2 and Colleagues 2017; Colleague and Author 2 2018). Science capital refers to an individual's science-related resources, attitudes and ways of thinking. The more science capital a young person has, the more likely s/he is to see themselves and to be recognised by others as being a 'science person', and to continue with science after it is no longer compulsory (Colleague and Author $12017)$.

Our project extended the Bourdieusian framework of capital (resources), habitus (way of being in the world) and field (any particular context with its rules and structures that determine what is valued) to conceptualise student engagement with science (Archer 2017; Author 3 et al. in press). Student engagement with science is realised where habitus, capital and field are aligned and feed off each other. That is, for students whose resources, experiences and dispositions (or capital and habitus) are valued and supported within the 
science museum setting, engagement is likely. Others (e.g. with low science capital) will most likely find little connection with what is on offer in the visit and, consequently, display limited engagement with science. This lack of engagement, particularly among individuals from disadvantaged backgrounds, has been aptly pointed out in the literature (Dawson 2014, 2018; Feinstein and Meshoulam 2014; Tlili 2008). Such work has produced some powerful representations of disengagement by noting the institutional barriers that inhibit engagement. In addition to this work, we think it is of equal importance to document what engagement looks like when it does occur and what museums can do to capitalise on its occurrence. Our understanding of engagement is further informed by a social justice rationale, in that it seeks recognise and value student engagement in science museums in its different manifestations. We advocate the need to appreciate experiences of engagement, even when they do not strictly conform to typologies or 'legitimate' ways to engage with science. By drawing attention to the dynamics at play that allow for different kinds of engagement to occur, we make a point of bringing the museum field into the foreground. Here, the field includes not just the exhibits and facilitators encountered in a museum but also the conventions, rules and assumptions that underpin the setting. Hence, our paper is aimed at museum practitioners who can reflect on and influence the setting in ways that accommodate engagement further. In short, this sociological approach draws attention to the field outside of the visitor, in a fresh perspective that progresses the thinking about what equitable museum practice might look like. This paper addresses the following question: What might moments of engagement look like in a science museum and what circumstances seem to promote them?

\section{Methods}

\section{Research design}

The study presented here can be conceptualised as a small-scale, exploratory case study which forms part of a larger project. Our study is qualitative in nature, which allows us the 
necessary flexibility to explore our research question in an open fashion (Miles \& Huberman, 1994), while guided by our developing conceptualisations and understandings of engagement in a museum context (Author 3 et al. in press).

One strand of work within the wider project included activities related to school trips and follow-up visits with families. During the school trips, student presentations were filmed and the videos formed the basis of an online museum trail. Following the school visits, students were invited to return with their families to use the video trails they had created, as well as to visit the rest of the museum. The instances of activity during the family visits that we describe in the findings all occurred as they browsed the museum, rather than being part of the trails activity.

\section{Participants}

Year 7 (ages 11-12) and Year 8 (ages 12-13) students from two London, state-run secondary schools and their families provided the data analysed in this paper. Both schools were mixed gender, roughly average in terms of attainment, and had medium to high proportions of students eligible for free school meals (an indicator of social disadvantage) and who spoke English as an additional language. Additional information about participating classes and students is provided in Table 1, below.

---- Insert Table 1 about here ----

\section{Data collection}

For each class, a variety of forms of qualitative data was collected throughout the experience - before, during and after the trips to the museum. More specifically, observations were conducted and field notes taken during pre-visit lessons, during the class visit itself and later on during the family visit. A subset of students were selected to be audio recorded on the class and family visits, based on a range of characteristics (e.g. gender, ethnicity). They were also likely to be low to middle attaining in science and from relatively economically 
disadvantaged backgrounds, which was typical of most of the students in our project overall. The audio recordings from the visits were not directly transcribed (primarily due to resource constraints) but were listened to and used to flesh out and add detail to the written field notes from the visits, thus ensuring a very rich source of data for analysis. In addition, individual interviews were conducted with children who had attended the family days and, where possible, their parents were interviewed as well. These interviews explored topics related to experiences of and interest in science and cultural activities, with a focus on the family visits.

Finally, the three focal students featured in our case studies were selected after a review of all of our data (including classroom observations), as described below, and thus were also students for whom we had sufficient data to infer their science capital and habitus as well as engagement with science in the classroom.

\section{Analysis}

We approached the analysis in an iterative, open manner, drawing on the constant comparative method (Glaser and Strauss 2009) and systematically working back and forth between the data sources to identify instances of engagement. We began with repeatedly reviewing the field notes (augmented by audio recordings) from the visits, looking for instances of engagement. As mentioned in the introduction, our analytical approach to identifying moments of engagement was strongly informed by our conceptual framework for engagement developed in the wider study (Archer et al. 2016; Author 3 et al. in press). Although our analysis was heavily informed by this conceptualisation of engagement, our understandings became refined as we worked through our data to explore engagement in a museum context.

From this process, we pulled out several instances that we initially identified as possible examples of engagement. These included behaviours which have been noted in other studies (e.g. Barriault and Pearson) as indicative of engagement, such as observing intently, 
displaying emotions, questioning and talking about objects or other content encountered in the museum. These behaviours also tended to be of sufficient duration (i.e. at least a few seconds) in order to allow us to infer that they had the potential to support meaning making or the formation of some sort of connection. As a team, we reviewed and cross-checked them, referring to the broader conceptual framework, in order to verify we would classify them as engagement. We then attempted to explore what conditions seemed to support or elicit this engagement - characteristics of the young people themselves (i.e. habitus and capital), elements of the museum setting (field), and particularly the interaction between the two. To this end, we also drew upon supplementary data sources - such as interviews with pupils and their families - for additional insight (especially about students' science capital and habitus) that might help us interpret the data from the museum visits. In creating our case studies, we attempted to draw together what we knew or could infer about students' habitus and capital and related these features to the elements of the field, in order to explicate the engagement we observed.

Overall, we argue that our data offers illustrations of what is possible and insight into what might support engagement. We attempt to offer sufficient context and descriptive detail so that readers can determine for themselves the extent to which our findings might apply to other situations, consistent with the notion of trustworthiness in qualitative research (Lincoln and Guba 1985). While we make no claims of generalisability, we believe that 'fuzzy' generalisations (Bassey 2001) might be a possible outcome of this work. These are tentative propositions, 'expressed in the form: particular events may lead to particular consequences' (ibid 6), which illuminate what is possible and when such predictions are accompanied by thorough descriptions of the context, may be useful in informing action. The construct of a fuzzy generalisation is congruent with the aim of this paper - to show what engagement is 
possible and under what circumstances. We hope, then, that this work may be useful in promoting reflection among museum practitioners.

\section{Starting points: Identifying student engagement in science museums}

We structure our findings around illustrative examples of engagement from three students, Charis, Omari and Jasmine. For each of them, we present a vignette reflecting their school trip and then one from their family visit in order to give a clear flavour of what happened. Next, we draw upon our conceptual frame, as well as supplementary data, to interpret the vignettes and identify the possible alignments of habitus, capital and field that may have shaped the engagement we observed. Finally, in the discussion, we look across the three cases to reflect on the content and types of experiences (or characteristics of the museum field) that seem to have supported engagement.

\section{Vignettes}

\section{Charis: 'Is it real?' Engagement as curiosity}

Charis was in Year 8 (age 13) at the time of the visit and lived with her parents and three siblings in a small council flat (public housing). She is of Turkish heritage but speaks English as her first language. She is in a mixed-ability class for science and in lessons is generally engaged and on-task, though does not seem exceptionally interested. Drawing on observation and interview data, we suggest that she would seem to have relatively limited science capital. School trip

Early in the visit, Charis pulled a stethoscope out of the props bag, asking 'Is it real? Oh my God!' Next, in a medical gallery, Charis was fascinated to find out that the chemistry cabinet on display was real ('Oh my God!'). She wondered whether it might have Lister's fingerprints still on it, even though he had died over 100 years previously (in 1912). She remarked to the group, 'My nan has a tin from 1912. She wasn't alive then - it was her dad's'. 
Charis's group then proceeded to another medical gallery, where they began by looking at a diorama of open heart surgery from the 1980s and then a diorama of a Victorian amputation, in which they expressed disgust at the gangrenous (black) foot. ('Eeew, look at his foot!', 'That's grim!') The students moved on to a full-scale model of a pharmacy, which they could walk into. Charis also compared her experience in that part of the museum to Madame Tussauds. The pupils continued with their questions, asking about the dates the pharmacy was in use and what in the pharmacy was 'real' and what was a replica.

This pattern of expressing interest in what was real and what was a replica, as well as asking questions, making comments and wondering about objects continued throughout the visit, including the group's stop in another object-rich gallery, Making the Modern World. In that gallery, Charis again seemed particularly intrigued by objects that were somehow surprising (e.g. by medals for doctors, as she had not known that doctors were given medals) or unusual (e.g. a tractor engine that looked like a train in front).

\section{Family visit}

About two months after her school trip, Charis returned to the museum for a family day with her mother Leila and her 5-year-old brother Sonny. Her mother's behaviour was reminiscent of Charis's during the school trip - expressing fascination with what she saw (including whether it was real or not), commenting on objects, discussing them with both children and making multiple connections to her life. For instance, in the History of Medicine gallery, the mother stopped abruptly in front of the heart surgery diorama. Although it was set in the 1980s, it elicited a long story from Leila about her recent Caesarean section.

In the same gallery, Charis and her family moved on to the pharmacy model, which the mother said reminded her of an old-fashioned sweet shop in a nearby suburb. She also noted that there was a similar shop in another neighbourhood not far from their home, as well as pointing out the 'medicines' in the bottles to her son, explaining that they were 'not real'. 
The family continued interacting in a similar manner as they visited other galleries in the museum. For instance, they passed the Apollo 10 command module and were amazed that it was real, with Charis exclaiming, 'Imagine going up to space in that!'

\section{Interpretation}

Charis's behaviours observed during both her visits indicated considerable engagement with the objects on display. These included stopping, commenting, sharing ideas with others, pointing out objects to others, asking questions, displaying emotional reactions (e.g. 'eeew!', 'Cool!' and 'Oh my God!'), taking photos and making connections to her own experience and familiar objects. She and her mother were particularly engaged by objects that might be 'real', consistently asking about this and expressing fascination when they were. For them, this was clearly an engaging feature of the museum and one which helped hook them into the objects (even when they were not real - as with the medical dioramas and replicas). In addition, they would frequently place the objects in the narrative of their lives - comparing what they saw with their own experiences, which was effective in supporting engagement. Additionally, it seems that objects that, for this family, offered a balance between familiarity and novelty were particularly effective in encouraging connections with their lived experience. For instance, the 1905 pharmacy was recognised as a pharmacy (which is familiar), as well as reminding the mother of an 'old fashioned sweet shop' that was also familiar to her.

Although the mother had not been to this museum since childhood, she clearly felt comfortable and easily able to make connections to the objects, as did her daughter. That is, despite limited science capital it would seem that there is something in her habitus and capital more generally that helped her feel 'at home' in the rather unfamiliar field of this particular museum. In her post-visit interview, Charis remarked that her mother was consistently curious - always asking questions and making connections. This disposition - or habitus - 
would seem to have served her well in the museum. Moreover, interview data also highlighted that she did have experiences that she could draw upon in the museum, including regular visits to a local museum, chaperoning her children's class trips to museums and attending cultural events and festivals. Such experiences seem to have provided her with a degree of cultural capital which was useful in the museum. However, she did not possess a similar degree of economic capital to those of many middle-class families visiting the museum. Indeed, field notes reflect that she complained about the gift shop - nearly unavoidable but very expensive, and the cost of food, deciding that they would eat when they returned home. Thus, although her habitus and capital were aligned in many ways with the field of the museum, supporting persistent engagement throughout the visit, other aspects of the field (e.g. the additional costs in the museum) were not aligned with the mother's economic capital (or lack thereof), sending a strong message that in many ways the museum was not 'for them'. This tension reminds us that the museum's field is multifaceted and work needs to happen across a range of aspects to bring it into fuller alignment with visitors' habitus and capital and allow engagement to be maximised.

\section{Omari: Engagement through personal connections and family conversations}

Omari was also in Year 8 and lived with his mother and three brothers in a modern council flat. The family is from Bangladesh, although the boys were born in England, and they speak Bengali at home. The father had recently left the family and moved back to Bangladesh, which created considerable strain as the mother struggled to find work due to very limited English skills. Omari is in the same mixed-ability science class as Charis, and tends to be ontask, but quiet. Like Charis, he and his family have limited science capital; his mother left school at a young age and the family has never participated in any sort of 'structured' informal science experiences (e.g. visits, clubs). Despite this, Omari does express an aspiration to be an automotive engineer. 


\section{School trip}

In the morning, Omari and his peers visited a medical gallery, where they asked questions about a display of old bottles, asking, 'Is this blood?' 'Is this real?' The museum educator explained that the old bottles were to collect urine specimens. At this, they pulled faces and voiced a bit of disgust - 'Eeeew!!' They expressed similar reactions - a combination of fascination and mild horror - about old surgical instruments, including a saw used in amputations, sharing this information with a classmate from another group. Continuing the discussion about surgery, the museum educator explained that doctors used to perform surgery without anaesthetic, which Omari compared to his brother's recent tonsil surgery: 'They just gave him an injection and he fell asleep'.

Later in the same gallery, the group focused on a display about early vaccines. Omari asked, 'Is this the needle they used to use?' The museum educator confirmed and Omari responded, 'It's massive!! [Expletive!]' His classmate compared those vaccines to today's: 'This would have been way more painful than what we have now.' The group continued talking about vaccines they had had, with Omari asking how many vaccines they had been given as babies.

Upon encountering various cars in another gallery, Omari shared many facts about them with his classmates, including the purposes of various parts, how they were made, and their speed. He also had a lively discussion with a museum educator, talking about seat belts and the speed of various cars, as well as where they were manufactured: 'German cars are the best... heavy! Volkswagen!' He added that he wanted to be an engineer when he grew up.

\section{Family visit}

Several weeks after the school trip, Omari returned to the museum, bringing his mother and three younger brothers. During their visit, they explored a gallery about flight, where the boys engaged in extended and lively conversations about various objects on display. All four 
brothers engaged in several such conversations - pointing out planes (and air balloons, boats and other vehicles) to each other, discussing the functions of various features (e.g. fins, nose cones) and speculating about the purpose of some of the more unusual vehicles (e.g. stunt plane, helicopter in the back of a boat). Although the mother, whose English was very limited, did not participate as actively in the conversations, she observed her children intently and expressed considerable interest in many of the objects, often asking questions about them and commenting that they were 'good'.

\section{Interpretation}

Omari, as well as his classmates and brothers, demonstrated behaviours consistent with engagement, such as asking questions, displaying emotional responses to objects, sharing knowledge, discussing personal experiences and having extended interactions around content. The students' engagement with the displays of surgical equipment generally, and vaccines in particular, highlights the way in which a balance seems to have been struck between familiarity and novelty. While the objects themselves were of course unfamiliar, students could connect them to their own personal experiences of vaccines and surgery. At the same time, while these personal experiences were familiar and generally shared, they were not so commonplace as to render them uninteresting.

In addition, Omari's engagement with the cars on the class trip and in the flight gallery with his brothers reflects the way in which those objects afforded him the opportunity to share his interest and expertise. Moreover, the situation was also comfortable enough that it seems to have encouraged him to share his aspiration to be an engineer. That is, he was able to connect what he encountered in the museum to his career aspiration. From the perspective of our conceptual framework, it would seem that the alignment between Omari's habitus (e.g. his disposition to engage with particular objects) and capital (e.g. knowledge about how to find out information in a museum - perhaps partly derived from his school trip experience 
and knowledge about those objects) was sufficiently aligned with the field to produce the engagement that was observed (e.g. discussing, pointing, sharing, emotional expressions).

\section{Jasmine: Engagement with music performance in a science setting}

Jasmine was in Year 7 and was in the mixed-ability set for science in her school. She did not participate much in her science lessons and observations and interviews indicated she was more interested in drama and singing, aspiring to be a performer. Her family are from a working class, African-Caribbean background, with some members in the music and entertainment business. Overall, data suggest that the family, including Jasmine, have no particular affinity to science and fairly low science capital but had been to the Science Museum a few times previously.

\section{School visit}

Jasmine's class began their visit in the Space gallery, where Jasmine spent her time giggling and singing with a group of friends. She expressed no observable interest in the exhibits, but moved in the gallery space with confidence. During the visit, Jasmine and her friend Sharifa alternated wearing a microphone, which Jasmine took as an opportunity to perform whilst walking around the gallery. The microphone captured several 'staged' conversations between the two girls and quite a bit of singing:

Jasmine: I think I learnt a lot today. It was really fun, don't you think Sharifa?

Sharifa: (Giggling and in an exaggerated tone) Yes. It was fun innit? It was so much fun; we really learnt a lot of stuff.

Towards the end of the visit, when they realised they had not completed their assigned task, they began to move around very quickly, taking photos of all the large objects in the gallery and keeping only the ones they agreed were 'nice'.

Family visit 
A few months later Jasmine returned to the museum with her mother, Tyra, and father, Nelson. Nelson was keen for Jasmine to lead the way, giving her the museum map. Jasmine felt overwhelmed by the information on the map, saying she was unsure of where she wanted to go. They went through the Space gallery in which she stopped momentarily to point to the Apollo 11 display, which had featured in her class video. Nelson was keen to learn what they had found out when they shot the video on her class visit and asked his daughter many questions. However, Jasmine simply read its label out loud. The pattern of the father asking questions and Jasmine reading the label was repeated a few times throughout the visit.

Later in the visit, the family decided to stop in a gallery about the development of communication technology. After resting and Nelson talking about some recorded songs that were playing, the family noticed some old TV sets playing videos very quickly with funny music. Father and daughter looked amused and did a little dance to the music. They then planned the remainder of their visit together. On the way to the café for lunch, they spotted a bicycle used for Google map pictures, which appealed to Jasmine, who took 'selfies' beside it. She later tagged one of them with 'science' on social media.

After lunch, Jasmine led the family to an exhibit ('Sound bite') in the interactive Launchpad gallery, demonstrating how to use it (biting into a straw to hear music). Her parents followed her instructions and looked impressed, with Jasmine then exclaiming that she wanted to do this 'all the time'. At another exhibit, involving wiring a burglar alarm, Jasmine became frustrated but eventually worked out how to make an alarm buzz. Her parents let her lead but her father stopped asking constant questions. Instead, the whole family became absorbed in sound making activities, which they clearly enjoyed.

\section{Interpretation}

Jasmine's behaviour during both visits was not consistent with engagement with the science content of the museum. For instance, during the school visit, she and her friend looked at and 
hastily chose some objects only when they realised they were running out of time to hand back their worksheets. On the family visit, her father asked questions about the displays and encouraged her to take the lead, but she reluctantly read out labels and expressed no interest in elaborating.

Nevertheless, we could not argue that Jasmine remained completely disengaged throughout her visits. She was comfortable and confident enough to navigate the space and locate aspects of the displays relevant to her music and performance interests/experiences (habitus and capital). Her clearly marked personal preferences and 'favourite things' in the museum also reflected her emotional engagement with the setting. During the visit with her parents, there were several aspects of the experience clearly aligned with the family's music habitus and, as a result, their engagement could emerge and be sustained. Jasmine's moments of engagement in the museum might not necessarily match the exhibits' intended learning outcomes, but were enough for her to seem to feel a connection with the place. Consequently, although data reflect that Jasmine does not identify as a science person, she would seem to regard the science museum setting as a place for her, something she confirmed in the followup interview. In her case, the conditions of the field favoured a degree of engagement: the visits' set-up and some of the content aligned with Jasmine being and acting 'as herself' socialising with friends and family, and pursuing her regular interests - in the museum.

\section{Discussion}

Looking across our three vignettes, as well as throughout our dataset, we found instances of student engagement. Sometimes these moments were fleeting, other times there were more prolonged interactions but in all we saw overt behavioural indicators of engagement such as observing intently, displaying emotional reactions, drawing others' attention to objects, commenting on objects, asking questions and sharing ideas and information. We acknowledge that this attention to observable manifestations of engagement may miss more 
'covert' forms (e.g. reflecting on objects previously encountered) but our point is to focus on clear instances of engagement and in particular, on the field (what they were engaging with) as potentially informative of practice. The examples showcased in the vignettes suggest that manifestations of student engagement during visiting situations can be quite varied and nuanced. Nevertheless, the common aspect were the instances of alignment between personal habitus and capital, the students' dispositions and practices, and the field, the museum's conventions and rules, as well as its objects and exhibits. Although our focal students possessed relatively low science capital, they seemed to have other elements of capital and habitus that facilitated observable engagement in the field of the museum.

For Charis and her mother, curiosity and the tendency to ask questions and make connections were a personal and family trait or disposition (habitus) that aligned with the object-rich environment of the museum. Moreover, they both had some experience in such environments, which served as capital they could draw upon during their visits. Consequently, the museum space (or field) in this instance was a generally accommodating environment in which their engagement could occur, despite the occasional tensions between the field and other elements of the family's capital, such as their economic capital (or lack thereof). Broadly, though, the data suggest that their habitus and capital was sufficiently aligned with the field of the museum to produce the engagement we observed.

For Omari, the museum visit was also comfortable enough that it seems to have encouraged him to share his aspiration to be an engineer. His expertise and interest in cars (capital) seemed to fit well with what he encountered in the museum (field). While we do not have much information about his habitus (other than his interest) the engagement we observed leads us to infer that it likely aligned with the field of the museum. Moreover, his mother displayed dispositions such as curiosity and a tendency to ask questions, despite facing a language barrier in the form of very limited English, which is suggestive of a habitus 
well-aligned with the museum. Additionally, it does not seem unreasonable that Omari would have acquired a similar habitus through socialisation in the family home.

For Jasmine, the fact that family habitus and personal capital were not scienceoriented did not prevent her from displaying a broadly positive emotional response to the museum. The freedom to 'perform' during the class and family visits afforded by the field (including the activities on the visits), fostered an environment where she could engage with the museum's content. We observed Jasmine's engagement on a number of occasions, and although these were not narrowly focussed on science content, we would argue that they do 'count' in that these are valid ways to engage in the museum.

The examples presented above allow us to move the conversation beyond the polarity of full, 'legitimate' engagement (e.g. extended discussions around science content) versus disengagement. We interpret them as entry points, small successes on the museum floor with potential for expansion. The challenge for science museums is then to sustain, develop and make the most of these occasions. The first step towards this direction is to recognise and value instances of engagement.

To that end, it is noticeable that these students and their families were often engaged with the historical and familiar nature of the objects, rather than with the scientific content. This may be partly because these families had generally low levels of science capital. That is, visitors to places like science centres and science museums are likely to have medium to high levels of science capital, which helps them to feel 'at home' in such settings and supports their engagement with the science which forms a part of the field of the science museum. In the absence of science capital, our participants drew on other aspects of their capital which were aligned with the field of the museum - such as previous experience in such spaces, as well as knowledge and/or experience with some of the objects on display. We also note that the engagement that we observed occurred during experiences that were strongly scaffolded - 
as part of school trips or on a family visit accompanied by a researcher. We hypothesise that such scaffolding may have also increased the possibility of alignment between the habitus and capital of the visitors and the field of the museum, or brought what alignment there was to the surface, leading to engagement.

\section{Limitations}

The qualitative and open nature of the data collected precludes claims to representativeness. We cannot and do not claim that our participants are somehow 'representative' of a particular type of museum audience (such as visitors or 'non-visitors' or 'young people' and so forth). We also make no claims as to frequency or how 'typical' the instances of engagement we describe in the findings might be and urge caution in generalising from our findings to other, particularly non-science, settings. In addition, although we make some inferences about students' habitus and capital when we interpret their engagement, these constructs do offer a rich way of interpreting their behaviour. Moreover, other data collected suggest that these theoretically-informed inferences, where made, are not unreasonable and we argue that the in-depth, theoretically-grounded qualitative analyses we have presented have important implications for practice (Lincoln and Guba 1985).

\section{Conclusions and implications}

Reflecting on these case studies involving individuals with low levels of science capital and considering others whose habitus and capital may not be aligned with the field of a science museum, leads us to ask what are the 'points of connection' for these individuals and how can they be leveraged? For our three focal students and their families, and probably others as well, these connection points were related to content but not necessarily to science. In some instances, they might be categorised as 'history of science' and in others they were outside science (e.g. music and performance). We acknowledge that this might lead some to ask, 'Where is the science?' But we would counter by asking what is - or should be - the 
goal for the visit. Could it be to help to help all visitors, including those from diverse backgrounds, to make connections with the exhibitions and activities? Moreover, we argue that creating a welcoming environment in what has traditionally been an exclusionary space is a valuable goal in itself.

On the other hand, if the goal is to engage visitors with the science content itself, science museums need to think carefully about how that might happen - to consider what kinds of facilitation, interpretation and broader changes to the setting might be needed and even to clarify what engagement looks like (i.e. is it all about physical interaction?) Our data highlights that engagement is happening, but how might that be leveraged to support engagement with the science? One possibility could involve personalising and localising the content - going beyond just providing context to highlighting the links between the content and the lives of the visitors themselves. We acknowledge challenges with the idea of getting to know thousands of individual visitors personally, but it seems likely that there are certain patterns in what is local and personal across multiple visitors. That is, getting to know some visitors well - by eliciting their experiences and ideas, is likely to yield insights that can help connect with a wider group of visitors. A related approach involves supporting the development of visitors' science capital by helping them come to see 'science places' (such as science museums) as 'for them'. Such a goal does not focus on 'communicating content' but rather involves the recognition and support of attitudes and dispositions (habitus) visitors bring with them.

This focus on science capital not only involves a shift towards emphasising visitors' habitus, rather than science literacy or content knowledge but also, crucially, towards attending to the environment, or field, of the museum itself. From a theoretical perspective, our data suggests that there were elements of the field that seemed to be better aligned with the habitus and capital of our participants. Put differently, some guidance as to how science 
museums might change the 'field' is found in our data. In particular, the objects with which our focal visitors engaged tended to strike a balance between familiarity and novelty. One such example was that of syringes historically used for vaccinations found in a medical gallery. While the object was novel - students had never encountered it before, they could also connect it with their own experience of injections. Likewise, objects that piqued curiosity also seemed to be effective points of connection. In some cases, these objects evoked questions around authenticity ('is it real?') or had a 'wow' factor (such as the Apollo 10 command module). Of course, which objects in the field of a science museum strike that balance between familiarity and novelty, connect with visitors' lived experience or elicit curiosity will vary depending on the collection and, crucially, the visitors themselves. Nevertheless, we would argue that visitor research can make it possible for museums to discover objects that are 'likely candidates' in this respect, that link to visitor interests or shared experiences. Research on authenticity has also highlighted the ways in which 'real' objects can support engagement and has begun to identify dimensions of authenticity or features that lead to judgements of authenticity (Frazier, Gelman and Wilson 2009; Hampp and Schwann 2014). Regardless of which characteristics support the formation of personal connections with an object, it is clear that authenticity is valued but is also ultimately constructed by the visitor, reflecting, we would argue, a link between an individual's habitus and capital and the object chosen for display (which is part of the field of the museum).

To facilitate such connections with their collections and experiences, we would also encourage museums to consider the field more broadly - to reflect on whose stories are told, whose images and objects are displayed, and to attempt to modify other elements (e.g. monolingual signage, physical barriers around entry, costs of items in the shops and cafes, and 'scowling security guards', as mentioned by one of the students) as well to contribute to a message that a broad range of visitors is welcome - not just those with the 'right' sort of 
habitus and capital, which are already aligned with the field of the museum. It is strategic and structural changes, or changes to the field, that are required to open up the museum experience to visitors who have been 'othered' by existing practices (Archer et al. 2016; Dawson, 2014, 2018; Feinstein and Meshoulam 2014), and thus increase the likelihood of moments of engagement for more individuals.

In sum, we argue that there is indeed engagement in the field of the science museum, just not necessarily engagement with the science. Does it matter? We would argue that it does not and that perhaps museums should shift their goal from engaging people with science (literacy), to engaging them with science as culture. We encourage science museums to broaden what 'counts' as a successful visit - every (positive) engagement (with objects, with interpretation, with staff) in a 'science-y' place is significant, even if it is not with the science behind the collection. We urge science museums to value any engagement and to think deeply about how they can modify the field, their field, to send a message to more visitors especially those from groups traditionally marginalised from science - that science museums are 'for them'.

\section{Funding}

This work was supported by [funder].

\section{References}

Archer, Louise. 2017. "Young people, science, engagement \& participation: a 'science capital' approach." Invited keynote presentation at the annual conference for the Association for Science Education, Reading, January 4-7.

Archer, Louise, Emily Dawson, Amy Seakins, and Billy Wong. 2016. "Disorientating, Fun or Meaningful? Disadvantaged Families' Experiences of a Science Museum Visit.” Cultural Studies of Science Education 11 (4): 917-939. doi: 10.1007/s11422-015$9667-7$

Author 2 and colleagues. 2017. School Science Review. 
Author 3 and colleagues. In press. Science and Education.

Author 3 and colleagues. 2017. [Teaching manual.]

Azevedo, Roger. 2015. "Defining and Measuring Engagement and Learning in Science: Conceptual, Theoretical, Methodological, and Analytical Issues." Educational Psychologist, 50 (1): 84-94. doi.: 10.1080/00461520.2015.1004069

Barriault, Chantal and David Pearson. 2010. "Assessing Exhibits for Learning in Science Centers: A Practical Tool." Visitor Studies 13 (1): 90-106. doi:10.1080/10645571003618824

Bassey, Michael. 2001. "A Solution to the Problem of Generalisation in Educational Research: Fuzzy Prediction.” Oxford Review of Education 27 (1): 5-22. doi: $\underline{10.1080 / 03054980123773}$

Bell, Philip, Bruce Lewenstein, Andrew Shouse, and Michael Feder, eds. 2009. Learning Science in Informal Environments: People, Places, and Pursuits. Washington, D.C.: The National Academies Press.

Bitgood, Stephen. 2013. Attention and Value: The Keys to Understanding Museum Visitors. Walnut Creek, CA: Left Coast Press.

Block, Florian, Hammerman, James, Horn, Michael, Spiegel, Amy, Christiansen, Jonathan, Phillips, Brenda, Diamond, Judy, Evans, E. Margaret, and Chia Shen. 2015."Fluid grouping : Quantifying group engagement around interactive tabletop exhibits in the wild."CHI 2015: Proceedings of the 33rd Annual ACM Conference on Human Factors in Computing Systems. Association for Computing Machinery (ACM): 867876. doi: $10.1145 / 2702123.2702231$

Boekaerts, Monique. 2016. "Engagement as an Inherent Aspect of the Learning Process." Learning and Instruction 43: 76-83. doi: 10.1016/j.learninstruc.2016.02.001 
Colleague and Author 1. 2017. [Book.]

Colleague and Author 2. 2018. Pedagogy, Culture \& Society.

Colleagues and Author 1. 2015. Journal of Research in Science Teaching.

Dancstep (née Dancu), Toni and Lisa Sindorf. 2016. Exhibit Designs for Girls' Engagement: A Guide to the EDGE Design Attributes. San Francisco: Exploratorium.

Dawson, Emily. 2014. “'Not Designed for Us': How Science Museums and Science Centers Socially Exclude Low-Income, Minority Ethnic Groups.” Science Education 98 (6): 981-1008. doi: 10.1002/sce.21133

Dawson, Emily. 2018. "Reimagining Publics and (non)Participation: Exploring Exclusion from Science Communication through the Experiences of Low-Income, Minority Ethnic Groups.” Public Understanding of Science. Advance Online Publication. doi: $\underline{0.1177 / 0963662517750072}$

Dicks, Bella. 2016. “The Habitus of Heritage: A Discussion of Bourdieu's Ideas for Visitor Studies in Heritage and Museums." Museum \& Society 14 (1): 52-64.

Falk, John and Lynn Dierking. 2000. Learning from Museums. Visitor Experiences and the Making of Meaning. New York: Alta Mira Press.

Falk, John and Lynn Dierking, 2013. The Museum Visitor Experience Revisited. Walnut Creek, CA: Left Coast Press

Feinstein, Noah, and David Meshoulam. 2014. "Science for What Public? Addressing Equity in American Science Museums and Science Centers." Journal of Research in Science Teaching 51 (3): 368-394. doi: 10.1002/tea.21130 
Frazier, Brandy N., Susan A. Gelman, and Alice Wilson. 2009. "Picasso Paintings, Moon Rocks, and Hand-Written Beatles Lyrics: Adults' Evaluations of Authentic Objects.” Journal of Cognition and Culture 9 (1-2): 1-14.

Fredricks, Jennifer, Phyllis Blumenfeld, and Alison Paris. 2004. "Student Engagement: Potential of the Concept, State of the Evidence." Review of Educational Research 74: 59-109. http://dx.doi.org/10.3102/00346543074001059

Glaser, Barney, and Anselm Strauss. 2009. The Discovery of Grounded Theory: Strategies for Qualitative Research. London: Transaction Publishers.

Gutwill, Joshua, Nina Hido, and Lisa Sindof. 2015. "Research to Practice: Observing Learning in Tinkering Activities." Curator 58 (2): 151-168. doi: 10.1111/cura.12105

Hampp, Constanze, and Stephen Schwan. 2014. "The Role of Authentic Objects in Museums of the History of Science and Technology: Findings from a Visitor Study.” International Journal of Science Education, Part B 5 (2): 161-181.

Hauan, Nils Petter, and Stein Dakert Kolstø. 2014. "Exhibitions as Learning Environments: A Review of Empirical Research on Students' Science learning at Natural History Museums, Science Museums and Science Centres.” Nordic Studies in Science Education, 10(1): 90-104.

Hillman, Thomas, Weilenmann, Alexandra, Jungselius, Beata and Tiina Leino Lindell. 2016. "Traces of engagement: narrative-making practices with smartphones on a museum field trip." Learning, Media and Technology, 41(2),: 351-370 doi: $10.1080 / 17439884.2015 .1064443$

Humphrey, Thomas, and Joshua Gutwill, eds. 2005. Fostering Active Prolonged Engagement: The Art of Creating APE exhibits. Walnut Creek, CA: Left Coast Press.

Knutson, Karen, Mandela Lyon, Kevin Crowley and Lauren Giarratani. 2016. "Flexible Interventions to Increase Family Engagement at Natural History Museum Dioramas.” Curator 59 (4): 339-352. doi:10.1111/cura.12176 
Lincoln, Yvonna S., and Egon G. Guba. 1985. Naturalistic Inquiry. London: Sage Publications.

Miles, Matthew, and Michael Huberman. 1994. Qualitative Data Analysis: An Expanded Sourcebook. Thousand Oaks: Sage.

Mutjaba, Tamjid, Lawrence, Martin, Oliver, Mary and Michael J. Reiss. 2018. "Learning and engagement through natural history museums. "Studies in Science Education, 54(1): 41-67. doi: 10.1080/03057267.2018.1442820

Schwan, Stephan, Grajal, Alejandro and Doris Lewalter. 2014. "Understanding and Engagement in Places of Science Experience: Science Museums, Science Centers, Zoos, and Aquariums.” Educational Psychologist. 49 (2): 70-85. doi: $\underline{10.1080 / 00461520.2014 .917588}$

Sinatra, Gale, Benjamin Heddy and Doug Lombardi. 2015. "The Challenges of Defining and Measuring Student Engagement in Science.” Educational Psychologist, 50 (1): 1-13. doi:10.1080/00461520.2014.1002924

Tlili, Anwar. 2008. "Behind the Policy Mantra of the Inclusive Museum: Receptions of Social Exclusion and Inclusion in Museums and Science Centres." Cultural Sociology 2 (1): 123-147. doi: $10.1177 / 1749975507086277$

Zimmerman, Heather, Perin, Suzanne and Philip Bell. 2010. "Parents, Science, and Interest." Museums \& Social Issues, 5 (1): 67-86. doi: 10.1179/msi.2010.5.1.67 